\title{
Opioid use disorder treatment disruptions during the early COVID-19 pandemic and other emergent disasters: a scoping review addressing dual public health emergencies
}

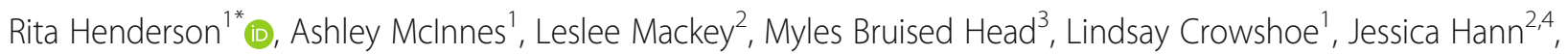
Jake Hayward ${ }^{2}$, Brian R. Holroyd ${ }^{2,5}$, Eddy Lang ${ }^{5,6}$, Bonnie Larson ${ }^{1}$, Ashley Jane Leonard ${ }^{7}$, Steven Persaud ${ }^{1}$, Khalil Raghavji ${ }^{8}$, Chris Sarin ${ }^{9,10}$, Hakique Virani ${ }^{8,11}$, Iskotoahka William Wadsworth ${ }^{3,12}$, Stacey Whitman ${ }^{13}$ and Patrick McLane ${ }^{2,5}$

\begin{abstract}
Background: During public health emergencies, people with opioid use disorder (PWOUD) may be particularly impacted. Emergent disasters such as the COVID-19 pandemic disrupt already-strained harm reduction efforts and treatment availability. This study aims to answer three research questions. How do public health emergencies impact PWOUD? How can health systems respond to novel public health emergencies to serve PWOUD? How can the results of this scoping review be contextualized to the province of Alberta to inform local stakeholder responses to the pandemic?

Methods: We conducted a scoping review using the 6-stage Arksey and O'Malley framework to analyse earlypandemic and pre-pandemic disaster literature. The results of the scoping review were contextualized to the local pandemic response, through a Nominal Group Technique (NGT) process with frontline providers and stakeholders in Alberta, Canada.

Results: Sixty one scientific journal articles and 72 grey literature resources were included after full-text screening. Forty sources pertained to early COVID-19 responses, and 21 focused on OUD treatment during other disasters. PWOUD may be more impacted than the general population by common COVID-19 stressors including loss of income, isolation, lack of rewarding activities, housing instability, as well as fear and anxiety. They may also face unique challenges including threats to drug supplies, stigma, difficulty accessing clean substance use supplies, and closure of substance use treatment centres. All of these impacts put PWOUD at risk of negative outcomes including fatal overdose. Two NGT groups were held. One group $(n=7)$ represented voices from urban services, and the other $(n=4)$ Indigenous contexts. Stakeholders suggested that simultaneous attention to multiple crises, with adequate resources to allow attention to both social and health systems issues, can prepare a system to serve PWOUD during disasters.
\end{abstract}

\footnotetext{
* Correspondence: rihender@ucalgary.ca

'Department of Family Medicine, University of Calgary, 2500 University Drive NW, Calgary, AB T2N 1N4, Canada

Full list of author information is available at the end of the article
}

(c) The Author(s). 2021 Open Access This article is licensed under a Creative Commons Attribution 4.0 International License, which permits use, sharing, adaptation, distribution and reproduction in any medium or format, as long as you give appropriate credit to the original author(s) and the source, provide a link to the Creative Commons licence, and indicate if changes were made. The images or other third party material in this article are included in the article's Creative Commons licence, unless indicated otherwise in a credit line to the material. If material is not included in the article's Creative Commons licence and your intended use is not permitted by statutory regulation or exceeds the permitted use, you will need to obtain permission directly from the copyright holder. To view a copy of this licence, visit http://creativecommons.org/licenses/by/4.0/. The Creative Commons Public Domain Dedication waiver (http://creativecommons.org/publicdomain/zero/1.0/) applies to the data made available in this article, unless otherwise stated in a credit line to the data. 
Conclusion: This scoping review and NGT study uncovers how disasters impact PWOUD and offers suggestions for better serving PWOUD.

Keywords: Coronavirus, Disaster planning, Opioid epidemic, Emergency, Health services, Opioid agonist treatment, Medication assisted treatment, Review

\section{Background}

When COVID-19 was declared a global public health emergency by the World Health Organization in March 2020, the opioid crisis was already impacting communities across Canada. Early public health documents highlighted that PWOUD may have more severe outcomes if infected with COVID-19, due to poorer baseline health and increased risk of transmission due to social inequities [1]. COVID-19 physical distancing measures also disrupt usual care and create new challenges for providers and public health decision-makers. Opioid Agonist Treatment (OAT) is the recommended treatment for OUD and increased morbidity and mortality are observed when OAT is interrupted [2]. In Canada, a surge of overdose-related deaths occurred early in the pandemic, as individuals became more likely to use drugs alone, with less access to services and supports to mitigate harms [3]. This study aims to answer three research questions. How do public health emergencies impact PWOUD? How can health systems quickly respond to novel public health emergencies to serve PWOUD? How can the results of this scoping review be contextualized to the province of Alberta to inform local stakeholder responses to the pandemic?

\section{Methods}

We conducted a scoping review using Arksey and O'Malley's six stage scoping review methodology [4] to: i) identify research questions; ii) identify relevant sources; iii) select sources; iv) chart data; v) collect, summarize; and report results; and vi) consult stakeholders.

\section{Identifying research questions}

We identified our research questions in partnership with operational leaders and service providers in emergency and addiction care in the context of rising opioid deaths in Alberta early in the COVID-19 pandemic. In addition to our scholarly, knowledgegenerating purpose, we had the knowledge translating purpose of contextualizing findings to Alberta. Following scoping review methods, our questions were refined throughout the course of the study as we gained familiarity with the literature, until they reached the final form reported in our introduction.

\section{Identify and select sources}

To identify scientific literature, a librarian (AL) and research assistant searched 10 electronic databases in May/June 2020 with search terms related to: disease outbreaks or disasters; opioid and substance use disorder; health care services and access (Table 1; full search strategy available in Additional file 1).

Duplicates were removed and results screened for inclusion criteria through title, abstract, and full text review (Fig. 1). Final inclusion criteria were studies that: (i) were published in a scientific journal from 2000 to 2020; (ii) provided insight on PWOUD; (iii) informed changes to service delivery, care and access to treatment; (iv) examined a natural disaster, pandemic or crisis situation; and (v) had full text available. Since English search terms were used, only English results were identified.

To gather grey literature (i.e., non-academic sources), a librarian (AL) completed Google searches using six search strings in June 2020, limiting results to the COVID-19 pandemic, Canadian sources, and the top 100 results of each search string for manageability (see Additional file 1). Websites identified by the study team were also searched for key words (e.g., "COVID-19" OR coronavirus AND opioids OR "opioid use disorder" OR "substance use disorder"). Grey literature inclusion criteria were: (i) Canadian source; (ii) related to opioid use, services and supports; and (iii) specific to COVID-19. We limited our inclusion criteria for grey literature to Canadian sources as a matter of manageability, and given stakeholder interest in locally-applicable contemporary information.

Multiple team members were involved in each step of title and abstract screening, as well as full text screening, to elaborate upon and achieve consensus on inclusion criteria and application of these criteria. As per scoping review methods, the reason for having multiple team members involved in screening was to enhance understanding of the literature and its relevance to the research questions [4].

\section{Charting data}

Tools for data extraction were developed and revised under the supervision of the first and last authors. We extracted source aims and methodology (when applicable), country, health service, disaster examined, disaster impacts (including affected populations and service disruptions), service adaptations, as well as resource type 
Table 1 Scientific literature search strategy

\begin{tabular}{ll}
\hline Databases searched & Search terms \\
\hline Ovid Medline, APA PsycINFO, CINAHL Complete, LitCOVID, WHO COVID-19 & COVID-19, Coronavirus, MERS-CoV, Middle East Respiratory Syndrome \\
database, TripPro, Science Direct (which included searches in Science Dir- & Coronavirus, Severe Acute Respiratory Syndrome, disease outbreak, influ- \\
ect Covid -19 Research database \& Elsevier 1Science Coronavirus Re- & enza, opioid, opioid use disorder, substance use disorder, disaster, natural \\
search Repository), Embase, Web of Science, and Ovid Cochrane Database & $\begin{array}{l}\text { disaster or mass disaster, health care access, community mental health } \\
\text { of Systematic Reviews }\end{array}$ \\
& $\begin{array}{l}\text { service, primary health care, community care, telehealth, health care } \\
\text { disparity }\end{array}$
\end{tabular}

for grey literature (e.g. policy document, practice guideline, news article). Three reviewers were involved in data extraction, with $100 \%$ of scientific literature and $20 \%$ of grey literature extraction cross-checked by a second reviewer to enhance relevance and comprehensiveness of extracted information.

\section{Collecting, summarizing and reporting results}

Literature review results were thematically outlined in information sheets in which analysts recorded common issues and ideas that appeared within sources, arranging these in bullet points with citations to relevant sources. Draft information sheets formed the basis for team discussion and organization of bullets under thematic headings. The information sheets formed an interim stage in analysis and were provided to stakeholders during Nominal Group Technique (NGT) sessions (discussed below) as a basis for co-interpretation of findings. Key themes presented to the stakeholders were: 1) increased risks during disasters for PWOUD, 2) models of care

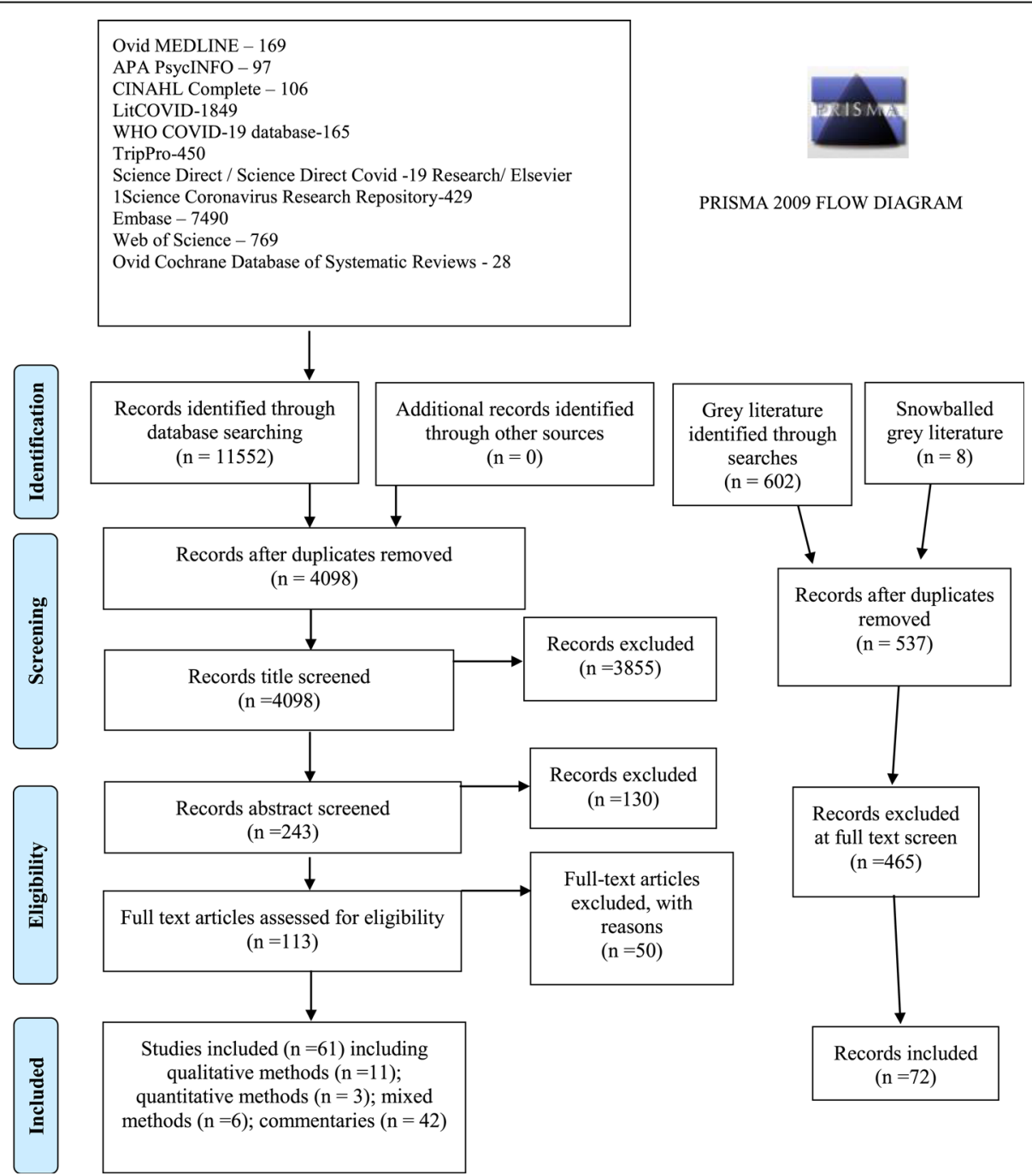

Fig. 1 Literature search and study selection 
adaptations, and 3) cross-systems implications. Final tables of results, as they appear in this manuscript, were created based on stakeholder input. Our development of extraction forms, information sheets and final manuscript tables are in keeping with Levac, Colquhoun and O'Brien's elaboration upon the Arksey and O'Malley framework, and their explanation that creation of data reporting products is part of the analysis work within qualitatively driven scoping reviews [5]. Overall, we adopted a generic qualitative approach involving reduction and display of data, in order to draw conclusions about relationships within the data and reach overarching themes $[6,7]$.

Reconsidering our results with stakeholders who work in the field of interest is an effort to enhance the rigour of our analysis through triangulation of perspectives, as well as a strategy for optimizing relevance of findings for health practitioners. Contextualizing scoping review results to the local pandemic response in Alberta is also a key component of this project, as universal or generalized approaches to care are not effective across diverse settings and populations.

\section{Consulting stakeholders}

A NGT was selected for its collaborative approach to building consensus between diverse, multi-sectoral knowledge users, for its attention to context, and as an effective knowledge mobilization method, as the engaged stakeholders can apply the evidence within their spheres of influence. This approach supports a broad view of the healthcare system integrated with Indigenous ways of knowing, including attention to community, relationships and healing the whole person (see [8]). The NGT is also valuable for work on stigmatized behaviours such as substance use, as the focus on building consensus helps to mitigate the likelihood of divisive partisanship that could prevent reflection on systems issues. NGT attendees are co-investigators and co-interpreters of the data, rather than traditional study participants, and so did not sign ethics consent forms. Not all participants in the NGT met authorship criteria at final submission, and not all co-authors attended NGT sessions.

NGT groups were composed of care providers, systems-level decision-makers, and patient advocates from Alberta, Canada, as well as representation from First Nations stakeholders. Stakeholders were invited to identify where the literature was reflective of their own experiences in service settings during the early days of the COVID-19 pandemic and where the literature could better inform and support their practices. They contributed ideas and engaged in moderated discussions to prioritize core insights about the literature data and its limitations [9]. Notes were taken during NGTs by multiple team members and core insights were generated based on these notes. NGT stakeholders reviewed, revised and validated core insights presented in tables and texts.

\section{Results}

After full text screening, 61 scientific journal sources met inclusion criteria, though these were primarily commentaries $(n=42,60 \%)$ (Table 2). Peer-reviewed literature included 11 qualitative, three quantitative, and five mixed methods sources $(n=19)$. Forty sources pertained to early COVID-19 responses, 12 focused on OUD treatment during hurricanes and nine focused on OUD treatment during other disasters (e.g., 9/11, heatwaves, riots, earthquakes and disasters in general). We also synthesize COVID-specific scientific and grey literature below. Seventy-two grey literature results met inclusion criteria (See Additional file 2 for a full list of included scientific sources; Additional file 3 for a grey literature summary).

Literature review results - impacts of disasters on PWOUD The literature reports that PWOUD may be more impacted than the general population by COVID-19 stressors, including loss of income, isolation, lack of rewarding activities, housing instability, as well as fear and anxiety [10, 11] (See Additional file 4 for a literature summary sheet). They may also face unique challenges including threats to drug supplies, stigma, difficulty accessing clean substance use supplies (e.g. needles) and closure of substance use treatment centres) $[1,10,12]$. Stress is likely to worsen substance use issues and increase high risk or undesired use of substances [11, 1315]. This may be acutely felt by those accessing OAT or who consider themselves to be in recovery, particularly for low income and marginalized groups [10]. Scientific literature indicated early on that physical distancing causes isolation and lack of rewarding activities, possible risk factors for increased substance use, self-harm, domestic violence, and other mental health problems [11]. Stressors can lead to substance use disorder development, intensification of substance use, or renewed high risk or undesired use of substances for those whose OUD was stably managed through treatment [13-15]. PWOUD may also experience increased difficulty obtaining sufficient supplies (e.g. food, substances and clean supplies for substance use) to shelter in place for extended periods, heightening risks [1]. For instance, needle shortages may result in reuse or sharing, and in turn transmission of bloodborne diseases such as HIV and Hepatitis C [1]. These stressors were also common themes in peer-reviewed sources on previous disasters (see Table 3).

Literature reported reduced access to addiction treatment, recovery supports, and harm reduction services, leading to increased health and safety risks for PWOUD 
Table 2 Scientific source overview

\begin{tabular}{|c|c|c|c|}
\hline & COVID-19 Focus & Other Disaster & Total \\
\hline \multicolumn{4}{|l|}{ Methodology } \\
\hline Qualitative & 1 & 10 & 11 \\
\hline Quantitative & 0 & 3 & 3 \\
\hline Mixed Methods & 0 & 5 & 5 \\
\hline Commentary & 39 & 3 & 42 \\
\hline \multicolumn{4}{|l|}{ Region } \\
\hline United States & 24 & 15 & 39 \\
\hline Global & 7 & 1 & 8 \\
\hline Canada & 1 & 0 & 1 \\
\hline Other & 8 & 5 & 13 \\
\hline \multicolumn{4}{|l|}{ Health System } \\
\hline General & 13 & 6 & 19 \\
\hline Specialty or Addiction-focused & 20 & 11 & 31 \\
\hline Cross-Systems & 3 & 1 & 4 \\
\hline Other & 4 & 3 & 7 \\
\hline Total & 40 & 21 & 61 \\
\hline
\end{tabular}

[14]. Disruptions in OAT access can cause withdrawal symptoms, leading some to seek illicit supplies [25] and increasing the risk of overdose due to more toxic or new and unfamiliar products in circulation [14]. As well, periodic voluntary or involuntary abstinence also increases risk of overdose, and may have been more common early on during COVID-19 due to interruptions in treatment, efforts to shelter in place and changes in street-level drug supply [26]. Additionally, decreased access and availability of naloxone during the early COVID-19 period [15], and fears of COVID-19 transmission through nasal naloxone and due to a lack of

Table 3 Summary of findings from peer-reviewed sources on previous disasters

\begin{tabular}{|c|c|}
\hline Amplified Risk for PWOUD during Disasters & $\begin{array}{l}\text { Efforts to Mitigate Risk for PWOUD and their Essential Services } \\
\text { During and After Disasters }\end{array}$ \\
\hline $\begin{array}{l}\text { - Disasters create high-risk environments that exacerbate substance use } \\
\text { and risk of infectious disease spread [16]. } \\
\text { - After disasters, people who resume illicit drug use after a period of } \\
\text { abstinence or use of safer supply do so in a higher risk context. Decreased } \\
\text { purity of illicit supply has been noted after disasters and fears of scarce } \\
\text { supply can result in high risk behaviour like sharing of needles [16, 17]. } \\
\text { - Personal impacts such as decreased employment, difficulty accessing } \\
\text { basic needs, homelessness, lack of transportation, lack of information on } \\
\text { how to access OAT and other supports, discrimination and stigma may } \\
\text { result in the use of substances to cope with disaster contexts [16, 17]. } \\
\text { - Systems issues such as decreases or redirection in public health } \\
\text { spending towards disaster relief, disruption to substance use treatment } \\
\text { and disruption to harm reduction services increase risks for PWOUD after } \\
\text { disasters [18]. } \\
\text { - During and after disasters, psychological and emotional distress } \\
\text { increases for both PWOUD and staff of support programs who are also } \\
\text { personally experiencing the disaster [19]. } \\
\text { - Disruption of services after disasters and increase in homelessness }\end{array}$ & $\begin{array}{l}\text { - Efforts to ensure access to OAT include: Provision of take home dosing, } \\
\text { guest dosing at clinics other than the patients' usual clinic, delivering/ } \\
\text { mailing of medication to patients, mobile units and communication } \\
\text { strategies (e.g., individual phone calls, hotlines and social media) to } \\
\text { keep people informed on how to access treatment [21, 22]. } \\
\text { Other supports include: } \\
\text { - Mental health support for fear \& anxiety after disasters: lack of increase } \\
\text { in illicit drug use attributed to availability of mental health professionals, } \\
\text { support groups, and counsellors [23]. } \\
\text { - Internet-based modules providing psychoeducation and motivational } \\
\text { feedback focused on mental health and substance use issues after a } \\
\text { disaster [24]. } \\
\text { - Disaster planning that values cultural specificity and needs of people } \\
\text { who have disabilities, mental health issues, use substances, or are on } \\
\text { OAT to ensure providers, first responders, organizations, and emergency } \\
\text { managers are prepared for disaster scenarios [22]. } \\
\text { - Formal disaster plans and a central database containing dosing } \\
\text { information [21,22] and coordinated emergency laws [20]. }\end{array}$ \\
\hline
\end{tabular}
associated with some disasters cause psychiatric distress and may increase substance use [18], and displaced populations that rely on shelters can be met with unprepared or untrained staff [20].

- Disruptions in OAT services, inadequate take home dosing, lack of guest-dosing information at alternate clinic sites put PWOUD at increased risk for negative outcomes after a disaster $[19,21]$.

- When OAT care is disrupted, people turn to emergency departments for access to OAT medications. However emergency clinicians sometimes face barriers prescribing OAT or lack access to patient dosing information, resulting in inadequate or unsafe prescriptions [21]. 
personal protective equipment (PPE) may have resulted in less overdose rescues before PPE supplies stabilized and aerosol protocols were established [14].

COVID-19 also intensifies already-existing barriers to care for underserved populations [27], including through quick clinic closures in response to the pandemic, decreased access to supervised consumption sites (SCS), and increase of drug use in isolation [14]. Patients may experience increased difficulties navigating systems that are even less coordinated than before the pandemic, as attention focused on provider- and clinic-level emergent COVID-19 guidelines and protocols [28].

The correlate of increased risks and disruptions for PWOUD appeared in the literature through efforts to mitigate substance use risks during COVID-19. In some jurisdictions these included clinical guidelines for riskmitigation opioid prescribing and for reducing the risk of COVID-19 transmission [29], or shifting to telehealth, smaller patient numbers in group therapy, and hand sanitizer provision [13, 30]. One source suggested telemedicine combined with street outreach as a holistic approach, noting that tailored care has been shown to improve housing stability and mental health along with care access [31]. At a policy level, Health Canada published exemptions to make OAT-prescribing more flexible and decrease in-person visits though virtual initiation of OAT, longer length of prescriptions, reduction of urine tests and witnessed dosing requirements, verbal prescription transfers to pharmacies closest to the patient, delivery of OAT by pharmacies, and allowing friends and family of patients to pick up OAT doses [32]. Similar shifts in care and the argument to maintain disaster-driven shifts as good practice, as well as the need for disaster planning, were common themes in peer-reviewed sources on previous disasters (see Table 3).

\section{NGT results}

The first of the two NGT groups held $(n=7)$ represented voices from urban services, and the second $(n=$ 4) represented voices from Indigenous contexts including First Nations reserve settings. Stakeholders elaborated upon ideas present within the literature with issues faced in local contexts, as presented in Table 4. Stakeholders also felt key issues that they faced during the first months of the COVID-19 pandemic were not adequately discussed in the literature. NGT stakeholders felt that the intersectionality of multiple stigmatized identities should be acknowledged, noting that the literature missed differential impacts of COVID-19 disruptions on Indigenous people, who are impacted by racist

Table 4 Stakeholder Contextualization of Literature to Social Disruptions from COVID-19

\section{SOCIAL CONTEXT OF DISRUPTION}

What resonates from the literature?

Social - Greater substance use in isolation; scarcer spaces \& disrupted

isolation networks to more safely use drugs in groups.

- Increased illicit substance use from unfamiliar sources; drug supply shifts potentially increasing toxicity.

- Amplified quality of life vulnerabilities for PWOUD; "relapse" part of broader substance use intensification.

- Sudden income loss and difficulties to secure basic needs driving increased stress \& risk taking.

\section{Where could the literature go further?}

Intensified - Decreased overall support from social and health services due to adversities closures for physical distancing and planning needed to prepare for a communicable disease pandemic.

- Pandemic Income assistance disrupted eligibility for other social assistance, which sometimes led to loss of medication coverage and new barriers.

- Disparate approaches to mitigate risk, with pandemic efforts emphasizing COVID-induced barriers to care without sufficient attention to pre-existing gaps in care

- Disruptions differentially impact racialized, gender minority, housing insecure, and other vulnerable groups in specific ways that need to be better understood and addressed.

Stigma - Disruptions aggravate existing adversities \& decrease access to care for already underserved groups.

- While focus on stigma facing PWOUD is important, it may limit attention to intersectionality of multiple stigmatized identities, especially racial \& gender inequities.

\section{Paraphrase of Stakeholder Comments}

People coming out of incarceration or hospitals are finding their map of where to access normal services have changed, and many don't know how to navigate not just what is available, but don't have means via available transportation.

\section{Paraphrase of Stakeholder Comments}

The crisis for people experiencing OUD is worse than COVID. We have to compare these two epidemics locally (COVID \& overdose), we must call it a dual public health emergency. It 100\% affects all, just as infectious diseases do.

Need to look disparity in the eye, why treat COVID with urgency and take away resources and increase risks elsewhere?

It's like Maslow's hierarchy of needs ${ }^{7}$ : when on treatment for addiction, you're a bit tied to healthcare and there's a razor's edge of needs to satisfy at the same time, to eat and drink and stay alive in a toxic environment. We're seeing the system not meet those needs and being politicized. For Indigenous PWOUD, you have 500 years of colonization, then this pandemic that isolates and incarcerates people for trying to meet basic needs.

They're not bad people but the stigma that they face... people are dying because of racism. 
stereotypes that link Indigeneity to problematic substance use (see also [34]). Stakeholders also emphasized that early COVID-19 disruptions intensify adversities for people in precarious circumstances and increase risktaking to meet basic needs. Such risk taking may involve participation in informal (often criminalized) economies including sex work. Providers expressed concern that increased overdoses were partially due to responder uncertainty about the risk of contracting COVID-19 during an overdose response, though guidance documents were available in some jurisdictions [29].

Stakeholders took issue with Alberta public health authorities' perceived tendency to prepare for and respond to one crisis at a time, with limited capacity to tailor public health responses to the unique needs of PWOUD who will be predictably affected in unique ways by emergent disasters. For these stakeholders, system disconnection, the need for innovation, a dearth of up-to-date information and contextual guidance, and the need for public health to balance multiple crises at once, all converge in the need for systems and service accountability to PWOUD. Stakeholders reported there were many unknowns and very little support for community providers and pharmacies, with most of the initial resources directed to acute care. This was perceived to increase gaps in care, particularly for PWOUD who lack telephones or accessible transportation to sustain contact with their providers (e.g., pharmacists, physicians, social workers) during a disaster.

Providers emphasized that their regulated professional bodies require them to respond to the needs of their clientele and maintain high standards of practice. Yet they also outlined gaps in their ability to provide care without systems-level support. This undermines accountability to patients and to providers, who are susceptible to burnout without the resources necessary to support their patients.

Providers further noted that the neighboring province of British Columbia had early access to data and practice guidelines. They felt British Columbia seemed to engage in evidence-informed decision-making that took into account both social and health systems issues. Many providers reported turning to sources from British Columbia to guide their practice and understanding of the needs of PWOUD in their care. Stakeholders described uneven political responses within distinct jurisdictions, noting that health authorities in British Columbia increased capacity for risk mitigation opioid prescribing.

\section{Discussion: outcomes of COVID-19 disruptions}

Emergent disasters increase burden on PWOUD trying to meet basic needs (such as shelter, food, substances, and healthcare), and aggravate risk behaviour by intensifying reliance on informal economies, and more frequent (and dangerous) substance use in isolation. Disaster literature pre-COVID-19 shows that the intensification of adversities faced by PWOUD during disasters is predictable. Public health has little reason not to anticipate the unique consequences of emergent disasters for medically underserved or socially vulnerable groups. Preparation for how disasters will impact vulnerable populations, including PWOUD, should involve nurturing relationships between providers that patients access across complex health and social services systems (e.g., establishing lines of contact, mandating coordinated care). As shown by our review of grey literature, early COVID-19 public health guidelines generally did not attend to the social realities of PWOUD. In future, public health should anticipate negative effects of public health measures and new hazards for populations at risk for catastrophic results of combined crises, rather than focusing attention on one crisis at a time.

Early public health responses to the pandemic identified COVID-19 as the primary threat to life, yet local outcomes raise questions about this assumption. An Alberta Health report on opioid deaths from Spring 2020 reported the highest ever number of opioid-related deaths in a single three-month period in Alberta [35]. In March 2020, OAT clinic operations were disrupted due to the pandemic [35]. SCS data indicates a fall in service uptake in Spring 2020 following capacity reduction measures in adherence with public health distancing guidelines [36].

While the COVID-19 death rate would almost certainly have been higher without the public health measures, avoiding COVID-19 deaths and preventing overdose deaths need not be understood as goals in opposition to one another. The dual pubic health crises could be equally addressed through evidence-informed measures that anticipate and address patient needs. This review highlights that systems that are more attentive to social determinants of health and that prioritize contextually-tailored care are better prepared for disruptions as they emerge.

COVID-19 adaptations to OAT access have focused on flexibility measures (e.g. take-home dosing, telehealth, mobile clinics) that may have helped many, but have largely relied on individual patient and provider adaptations, without systemic supports. This lack of system and service accountability to address emergent patient needs early during disruptive events is avoidable and puts unnecessary burdens on patients and providers. We present recommendations for system and service accountability in OUD care during disasters in Table 5.

Predicting the needs of diverse populations and their providers could prevent systems from becoming overwhelmed. Systems can be supported and funded to be 
Table 5 System \& Service Accountability for Responsive OUD Care during Disaster-Driven Disruptions

\begin{tabular}{|c|c|c|}
\hline Context of Disruption & Public Health Mechanisms to Mitigate Risks & Expected Outcomes \\
\hline \multirow[t]{2}{*}{$\begin{array}{l}\text { Disasters focus attention on single risks \& } \\
\text { generalized solutions }\end{array}$} & $\begin{array}{l}\text { Prepare cross-systems protocols \& coordinate to } \\
\text { anticipate how disruptions affect populations ren- } \\
\text { dered at risk. }\end{array}$ & \multirow{2}{*}{$\begin{array}{l}\text { Mitigate multiple sources of risk by attending to } \\
\text { patients' as whole persons \& diverse populations in } \\
\text { widely varying social contexts. } \\
\text { Engage in theoretically and historically-informed } \\
\text { planning to anticipate risk \& project implementa- } \\
\text { tion to mitigate future risks. } \\
\text { Avoid using emergency departments as universal } \\
\text { safety nets during disasters. }\end{array}$} \\
\hline & $\begin{array}{l}\text { Anticipate, track, and address risks from emergent } \\
\text { disasters as they interact with risks from associated } \\
\text { social and health systems disruptions (e.g., impacts } \\
\text { of pandemic as well as of distancing measures). }\end{array}$ & \\
\hline
\end{tabular}

Orient health system data analytics to generate \& circulate knowledge on multiple sources of risk and population groups.

Lack of information transparency in decision-making perpetuates stigma \& produces policy inattentive to social determinants

Harm reduction \& contextually-tailored care
Address social determinants of population health inequities (including racism) by tailoring public health guidelines for socially vulnerable groups (e.g., feasible, accessible, effective measures).

Enhance supports linking social \& medical systems for vulnerable populations during disasters to prevent predictable intensification of adversities \& treat addictions services equitably with other chronic/pre-existing diseases services that received additional tools and guidelines.

Ensure safer supply of opioids and supplies to help PWOUD through an emergency, while helping them to access other components of care.

Empower systems \& service providers; shift burden to the system to minimize strain on patients.

Support providers with informed order sets, care pathways, lists of resources, and links to social service and community partners to enable them to provide high quality and contextually-tailored care.
Prevent misinformation and reduce stigma by grounding policy and service decisions in evidence around what drives increased risk from disasters (e.g., that disruption in financial situations of people in poverty increases negative outcomes)

The system accommodates more change than individual patients are expected to accommodate. The burden of trying to determine what constitutes high quality care or appropriate attention to patient needs is not put on individual, unsupported, providers or care settings acting in isolation, and is instead achieved through a collaborative public health system. more ready and less reactionary when the unexpected happens. Funded supports might include clinical and office space, as well as staff such as implementation leads, policy writers, planners, case managers, and social workers. Such funded supports can provide for informed approaches to both social realities and health systems issues, and examples of successful models exist. At the service level, health system navigation and case management for chronically ill and unstably housed patients has shown promise in addressing social determinants of health [37]. At the system level, the Emergency Strategic Clinical Network built referral pathways between emergency departments and addiction treatment clinics prior to the pandemic [38].

Such approaches, and the kinds of public health approaches requested by NGT stakeholders, are united by the concepts of harm reduction and contextually tailored care [39]. Hyshka and colleagues describe "ideal" harm reduction frameworks as reflecting 17 components "including a focus on preventing harm and not substance use per se, tailoring approaches to specific needs of populations, addressing underlying causes of drug-related harm, involving [persons who use drugs] in decisionmaking, [being] evidence-based, rights-orientated" and considering social determinants of health [40]. Ford-
Gilboe and colleagues describe contextually-tailored care as an approach that "expands the individually focused concept of patient-centered care to include offering services tailored to the specific health care organization, the populations served, and the local and wider social contexts [39]." Taken together, harm reduction and contextually-tailored care approaches suggest going beyond a focus on single issue responses to crises, and recognition that PWOUD cannot safely have their treatment or substance use interrupted during emergent disasters.

\section{Limitations}

The COVID-19 pandemic is now over a year old, and an important consideration for interpreting this review is our focus on novel public health disasters and early systems responses. COVID-19 has become a long-term event that is distinct from such disasters as hurricanes or terrorism events and more like the opioid crisis itself. Future research could examine COVID-19 literature to understand how health system approaches change over the course of such longer term disasters. Readers may judge for themselves the degree to which strained healthcare settings and pandemic-focused public health responses emphasizing physical distancing, which do not 
adequately support PWOUD, remain salient in light of successive COVID-19 "waves" and emergence of new coronavirus variants of concern.

\section{Conclusions}

This scoping review and NGT study uncovers how disasters impact PWOUD and offers suggestions for better serving PWOUD. Our contextualization of findings to Alberta may be useful as a guide for those considering contextualization of literature evidence to their own contexts. Informed approaches to addressing social determinants of health and patient needs are required for greater accountability to PWOUD early during emergent disasters. As a component of disaster preparedness, healthcare systems need to engage in planning for key patient populations such as PWOUD to ensure their care can be continued concurrent with the response to the disaster. Stakeholder contextualization of the literature to Alberta highlights gaps in multi-risk management, data and decision-making, and public health organizing to respond to heightened adversities for PWOUD early during the pandemic. Simultaneous attention to multiple crises, with adequate resources to allow attention for both social and health systems issues, can prepare a system to serve PWOUD during disasters.

\section{Abbreviations}

NGT: Nominal Group Technique; OAT: Opioid Agonist Therapy; OUD: Opioid Use Disorder; PPE: Personal Protective Equipment; PWOUD: People with Opioid Use Disorder; SCS: Supervised Consumption Site

\section{Supplementary Information}

The online version contains supplementary material available at https://doi. org/10.1186/s12889-021-11495-0.

Additional file 1. Supplementary Methods; this document provides the full search strategy including search terms

Additional file 2. Supplementary Results of Scientific Literature; this document provides a full list of the included scientific literature and brief overview of sources in a table with descriptions of pertinent findings

Additional file 3. Supplementary Results of Grey Literature, this document provides a brief summary of the grey literature, highlighting critical documents

Additional file 4. Literature Summary Sheet, this document provides infographics synthesizing the academic and grey literature according to three thematic areas (increased risk, risk mitigation, and cross-systems issues) that guided the NGT discussions

\section{Acknowledgments}

The research team would like to acknowledge the contributions of care providers in the consensus-building working groups. The research team also thanks research assistant Marisha Eccleston for her support in the literature review.

\section{Authors' contributions}

$\mathrm{RH}$ and PM conceptualized the research, led the analysis and contributed to writing the manuscript. AM and LM performed the literature screening, data extraction, and contributed to writing the manuscript. All authors $(M B H, L C$, JeH, JaH, BRH, EL, BL, AJL, SP, KR, CS, HV, IMW, SW) contributed to analysis and knowledge synthesis through Nominal Group Technique. All authors revised and provided input on manuscript drafts. All read and approved the final manuscript

\section{Authors' information}

$\mathrm{RH}$ has a PhD in the social sciences and is a models of care clinical researcher and Assistant Professor in Family Medicine and Community Health Sciences at the University of Calgary. PM is a PhD sociologist and health services researcher, and is Assistant Scientific Director of the Emergency Strategic Clinical Network (ESCN), Alberta Health Services, and Adjunct Assistant Professor of Emergency Medicine at the University of Albera. AM is a PhD social scientist and Research Associate in the Department of Family Medicine at the University of Calgary. LM is a Research Coordinator with the Department of Emergency Medicine at the University of Alberta. BRH is an emergency physician, Senior Medical Director of the ESCN, and Professor of Emergency Medicine at the University of Albera. EL is an emergency physician, Scientific Director of the ESCN, and Professor of Emergency Medicine at the University of Calgary. MBH worked as an Indigenous client navigator for addictions services for a safe consumption site, now closed, in the southern Alberta city of Lethbridge. LC is a family physician and Professor at the University of Calgary. JeH and JaH are emergency physicians. BL is an inner-city family physician working in harm reduction. AJL is a librarian for Alberta Health Services. SP, KR, and HV are physicians providing addictions care in Metro City Medical Clinics in the cities of Edmonton and Calgary, as well as to partnered First Nations via telehealth and on-site mobile units. CS is a Medical Officer of health and primary care lead for Alberta Region at First Nations and Inuit Health Branch of Indigenous Services Canada. IWW is a policy analyst and Blood Tribe member in the Blackfoot Confederacy. SW has been clinic nurse manager of the Calgary Opioid Dependency Program and the Injectiable Opioid Agonist Treatment (iOAT) Program.

\section{Funding}

This research was funded by Health Canada SUAP (Arrangement number 1819-HQ-000053) and CIHR COVID-19 MH \& Substance Use - Understanding Rapid System Transformations competition (Reference Number MS4 173111). The funding bodies had no role in the design of the study, data collection, analysis, and interpretation of data, or in writing the manuscript.

\section{Availability of data and materials}

All data generated or analysed during this study are included in this published article and its supplementary information files (methods, results 1 $\& 2$ and literature summary sheets). No other datasets were generated during this study.

\section{Declarations}

Ethics approval and consent to participate

This article does not contain any studies with human participants or animals performed by any of the authors. NGT attendees are co-investigators, and so did not sign consent forms.

\section{Consent for publication}

Not applicable.

\section{Competing interests}

The authors declare that they have no competing interests.

\section{Author details}

${ }^{1}$ Department of Family Medicine, University of Calgary, 2500 University Drive NW, Calgary, AB T2N 1N4, Canada. '2Department of Emergency Medicine, University of Alberta, 8440112 St. NW, Edmonton, AB T6G 2R7, Canada.

${ }^{3}$ Blood Tribe, Stand Off, Canada. ${ }^{4}$ Addiction Recovery and Community Health (ARCH) Team, Royal Alexandra Hospital, 10240 Kingsway NW, Edmonton, AB T5H 3V9, Canada. ${ }^{5}$ Emergency Strategic Clinical Network, Alberta Health Services, 10030 - 107 St NW, Edmonton, AB T5J 3E4, Canada. ${ }^{6}$ Department of Emergency Medicine, University of Calgary, 3330 Hospital Dr NW, Calgary, AB T2N 4N1, Canada. ${ }^{7}$ Knowledge Resource Service, Alberta Health Services, 10030 - 107 St NW, Edmonton, AB T5J 3E4, Canada. ${ }^{8}$ Metro City Medical Clinic, 150 - 9095 Ave SW, Calgary, AB T2P 3G5, Canada. ${ }^{9}$ Indigenous Services Canada, Suite 730, 9700 Jasper Avenue, Edmonton, AB T5J 4C3, Canada. ${ }^{10}$ Department of Community Health Sciences, University of Calgary, 
2500 University Drive NW, Calgary, AB T2N 1N4, Canada. ${ }^{11}$ Department of Medicine, University of Alberta, 8440112 St. NW, Edmonton, AB T6G 2R7, Canada. ${ }^{12}$ Treaty 7 Chiefs Alliance, 206 - 8408 Elbow Drive SW, Calgary, Alberta T2V 1K7, Canada. ${ }^{13}$ Addiction and Mental Health, Alberta Health Services, 10030 - 107 St NW, Edmonton, AB T5J 3E4, Canada.

Received: 25 January 2021 Accepted: 13 July 2021

Published online: 28 July 2021

\section{References}

1. Jenkins WD, Bolinski R, Bresett J, Van Ham B, Fletcher S, Walters S, et al. COVID-19 during the opioid epidemic - exacerbation of stigma and vulnerabilities. J Rural Health. 2021;37(1):172-4.

2. CRISM. CRISM National Guidelines for the Clinical Management of Opioid Use Disorder; 2018. p. 1-132. Available from: https://crism.ca/wp-content/ uploads/2018/03/CRISM_NationalGuideline_OUD-ENG.pdf

3. Tasker JP. Opioid deaths skyrocket, mental health suffers due to pandemic restrictions, new federal report says. CBC News [Internet]. 2020; Available from: https://www.cbc.ca/news/public-health-annual-report-opioid-deathsskyrocket-1.5780129.

4. Arksey H, O'Malley L. Scoping studies: towards a methodological framework. Int J Soc Res Methodol Theory Pract. 2005;8(1):19-32. https://doi.org/10.1 080/1364557032000119616.

5. Levac D, Colquhoun H, O'Brien KK. Scoping studes: advancing the methodology. Implement Sci. 2010;5(69):1-9.

6. Miles M, Huberman A. Qualitative data analysis: a sourcebook of new methods. Berverley Hills: Sage Publications; 1984.

7. Cooper S, Endacott R. Generic qualitative research: a design for qualitative research in emergency care? Emerg Med J. 2007;12:816.

8. Henderson RI, Wadsworth I, Healy B, Bill L, Mclnnes A, Danyluk A, et al. Healing the Whole Human Being: Realist Review of Best Practices and Contextual Factors for Preventing \& Treating Opioid Misuse in Indigenous Contexts in Alberta [Internet]. Calgary; 2021. Available from: http://www.a fnigc.ca/main/includes/media/pdf/digital.reports/Healing-The-Whole-Huma n-Being FINAL Digital.pdf.

9. Cantrill JA, Sibbald B, Buetow S. The Delphi and nominal group techniques in health services research. Int J Pharm Pract. 1996;4:67-74.

10. Khatri UG, Perrone J. Opioid Use Disorder and COVID-19: Crashing of the Crises. J Addict Med. 2020;14(4):e281.

11. Mota P. Avoiding a new epidemic during a pandemic: the importance of assessing the risk of substance use disorders in the COVID-19 era. Psychiatry res [internet]. 2020;290(may):113142 Available from: https://doi.org/10.1016/j. psychres.2020.113142.

12. Salisbury-Afshar EM, Rich JD, Adashi EY. Vulnerable populations: weathering the pandemic storm. Am J Prev Med. 2020;58(6):892-4. https://doi.org/10.1 016/j.amepre.2020.04.002.

13. Columb D, Hussain R, O'Gara C. Addiction psychiatry and COVID-19 - impact on patients and service provision. Ir J Psychol Med [internet]. 2020;1-15. Available from: https://www.ncbi.nlm.nih.gov/pubmed/32434597.

14. CCSA. Impacts of the COVID-19 Pandemic on People Who Use Substances: What We Heard. Candian Centre on Substance Use and Addiction [Internet] 2020 [cited 2020 Sep 14]. Available from: https://www.ccsa.ca/sites/default/ files/2020-07/CCSA-COVID-19-Impacts-on-People-Who-Use-SubstancesReport-2020-en.pdf

15. CCSA. CCENDU Alert: Changes Related to COVID-19 in the Illegal Drug Supply and Access to Services, and Resulting Health Harms: Canadian Centre on Substance Use and Addiction [Internet]. 2020 [cited 2020 Sep 14]. Available from: https://www.ccsa.ca/sites/default/files/2020-05/CCSACOVID-19-CCENDU-IIlegal-Drug-Supply-Alert-2020-en.pdf

16. Pouget ER, Sandoval M, Nikolopoulos GK, Friedman SR. Immediate impact of hurricane Sandy on people who inject drugs in new York City. Subst Use Misuse. 2015;50(7):878-84. https://doi.org/10.3109/10826084.2015.978675.

17. Matusow $H$, Benoit $E$, Rosenblum A. Challenges to opioid treatment programs after hurricane sandy: Impact, preparedness, and recovery. Drug Alcohol Depend [Internet]. 2015;156:e142 Available from: http://www. sciencedirect.com/science/article/pii/S0376871615007607.

18. Mackey TK, Strathdee SA. Big events and risks to global substance using populations: unique threats and common challenges. Subst Use Misuse. 2015;50(7):885-90. https://doi.org/10.3109/10826084.2015.983008.

19. Frank B, Dewart T, Schmeidler J, Demirjian A. The impact of $9 / 11$ on new York City's substance abuse treatment programs: a study of program administrators. J Addict Dis. 2006;25(1):5-14. https://doi.org/10.1300/J069v2 5n01_03.

20. Rutkow L, Vernick JS, Mojtabai R, Rodman SO, Kaufmann CN. Legal challenges for substance abuse treatment during disasters. Psychiatr Serv. 2012;63(1):7-9. https://doi.org/10.1176/appi.ps.2012000p7.

21. Elliott $L$, Benoit $E$, Matusow $H$, Rosenblum A. Disaster preparedness among opioid treatment programs: policy recommendations from state opioid treatment authorities. Int J Disaster Risk Reduct. 2017;23(October 2016):1529. https://doi.org/10.1016/j.jijrr.2017.05.001.

22. Blake D, Lyons A. Opioid Substitution Treatment Planning in a Disaster Context: Perspectives from Emergency Management and Health Professionals in Aotearoa/New Zealand. Int J Environ Res Public Health [Internet]. 2016;13(11). Available from: http://ovidsp.ovid.com/ovidweb. cgi? T=JS\&PAGE=reference\&D=med13\&NEWS=N\&AN=27834915.

23. Weiss L, Fabri A, McCoy K, Coffin P, Netherland J, Finkelstein R. A vulnerable population in a time of crisis: drug users and the attacks on the world trade center. J Urban Heal New York Acad Med. 2002;79(3):392-403.

24. Ruggiero KJ, Resnick HS, Acierno R, Carpenter MJ, Kilpatrick DG, Coffey SF, et al. Internet-based intervention for mental health and substance use problems in disaster-affected populations: a pilot feasibility study. Behav Ther. 2006;37(2):190-205. https://doi.org/10.1016/j.beth.2005.12.001.

25. Sun Y, Bao Y, Kosten T, Strang J, Shi J, Lu L. Editorial: challenges to opioid use disorders during COVID-19. Am J Addict. 2020;29(3):174-5. https://doi. org/10.1111/ajad.13031.

26. Stowe M-J, Scheibe A, Shelly S, Marks M. COVID-19 restrictions and increased risk of overdose for street-based people with opioid dependence in South Africa. South African Med J. 2020;110(6):12939.

27. Green TC, Bratberg J, Finnell DS. Opioid use disorder and the COVID 19 pandemic: a call to sustain regulatory easements and further expand access to treatment. Subst Abus [internet]. 2020;41(2):147-9 Available from: https:// doi.org/10.1080/08897077.2020.1752351.

28. Webster F, Connoy L, Sud A, Pinto AD, Katz J, et al. Can J pain [internet] 2020;4(1):125-8 Available from: https://doi.org/10.1080/24740527.2020. 1766855.

29. BCCSU. Risk Mitigation in the Context of Dual Public Health Emergencies: Interim Clinical Guidance [Internet]. 2020 [cited 2020 Sep 14]. Available from: https://www.bccsu.ca/wp-content/uploads/2020/04/Risk-Mitigation-inthe-Context-of-Dual-Public-Health-Emergencies-v1.5.pdf

30. Peavy KM, Darnton J, Grekin P, Russo M, Green CJB, Merrill JO, et al. Rapid implementation of service delivery changes to mitigate COVID-19 and maintain access to methadone among persons with and at high-risk for HIV in an opioid treatment program. AIDS Behav. 2020;24(9):2469-72. https:// doi.org/10.1007/s10461-020-02887-1.

31. Harris M, Johnson S, Mackin S, Saitz R, Walley AY, Taylor JL. Low barrier telebuprenorphine in the time of COVID-19: a case report. J Addict Med [Internet]. 2020;14(4):e136-8 Available from: https://dx.doi.org/10.1097/ADM. 0000000000000682.

32. Health Canada. Subsection 56(1) class exemption for patients, practitioners and pharmacists prescribing and providing controlled substances in Canada during the coronavirus pandemic 2020 Mar 19 [Internet]. 2020 [cited 2020 Sep 14]. Available from: https://www.canada.ca/en/health-canada/services/ health-concerns/controlled-substances-precursor-chemicals/policy-regula tions/policy-documents/section-56-1-class-exemption-patients-pharmacistspractitioners-controlled-substances-covid-19-pandemic.html

33. Heavy Head R, Blood N. Naamitapiikoan: Blackfoot influences on Abraham Maslow's developmental and organizational psychology. Alexandria: Microtraining Associates; 2011.

34. Government of BC. In plain sight: Addressing Indigenous-specific racism and discrimination in BC health care [Internet]. 2020. Available from: https:/engage. gov.bc.ca/app/uploads/sites/613/2020/11/In-Plain-Sight-Full-Report.pdf

35. Government of Alberta. Alberta COVID-19 Opioid Response Surveillance Report: Q2 2020 [Internet]. Edmonton AB; 2020. Available from: https:// open.alberta.ca/dataset/f4b74c38-88cb-41ed-aa6f-32db93c7c391/resource/ e8c44bab-900a-4af4-905a-8b3ef84ebe5f/download/health-alberta-covid-19opioid-response-surveillance-report-2020-q2.pdf.

36. Alberta Health Services. Safeworks monthly report - October 2020 Supervised Consumption Services [Internet] 2020. Available from: https:// www.albertahealthservices.ca/assets/info/amh/if-amh-sup-con-chumir-202 0-10.pdf

37. Dewsnap K, Kamran H, Rondeau K, Polachek A, Fabreau G, McBrien K. Assessing the impact of connect 2 care on the residential stability of 
homeless and vulnerably housed clients. Alberta Acad Rev. 2019;2(3):17. https://doi.org/10.29173/aar107.

38. McLane P, Scott K, Suleman Z, Yee K, Holroyd BR, Dong K, et al. Multi-site intervention to improve emergency department care for patients who live with opioid use disorder: a quantitative evaluation. CJEM. 2020;6:784-92.

39. Ford-Gilboe M, Wathen C, Varcoe C, Herbert C, Jackson B, Lavoi J. How equity-oriented health care affects health: key mechanisms and implications for primary health care practice and policy. Milbank Q. 2018;96(4):635-71. https://doi.org/10.1111/1468-0009.12349.

40. Hyshka E, Anderson-Baron J, Pugh A, Belle-lsle L, Hathaway A, Pauly B, et al. Principles, practice, and policy vacuums: policy actor views on provincial/ territorial harm reduction policy in Canada. Int J drug policy [internet]. 2019; 71:142-9 Available from: https://doi.org/10.1016/j.drugpo.2018.12.014.

\section{Publisher's Note}

Springer Nature remains neutral with regard to jurisdictional claims in published maps and institutional affiliations.

Ready to submit your research? Choose BMC and benefit from:

- fast, convenient online submission

- thorough peer review by experienced researchers in your field

- rapid publication on acceptance

- support for research data, including large and complex data types

- gold Open Access which fosters wider collaboration and increased citations

- maximum visibility for your research: over $100 \mathrm{M}$ website views per year

At $\mathrm{BMC}$, research is always in progress.

Learn more biomedcentral.com/submissions 